\title{
Intravenous Immunoglobulin (IVIG) for the Therapy of Autoimmune Disorders
}

\author{
STANLEY A. SCHWARTZ ${ }^{1}$
}

Accepted: December 14,1989

The weight of evidence from numerous clinical studies supports the use of IVIG, particularly at higher doses, in the treatment of a wide range of autoimmune disorders. Extensive experience has documented the safety of IVIG therapy but its present relatively high cost necessitates firmly establishing its efficacy. There is an acute need to define those disease states where IVIG is indicated and effective. Large-scale, possibly multicentered, clinical trials employing rigorous controls will resolve these questions. Concurrent fundamental immunologic studies will elucidate the mechanisms underlying the clinical effects. We are experiencing an exciting new era of effective immunotherapies and intravenous gamma-globulin preparations have already secured an important place in the therapeutic armamentarium. While one must guard against unsubstantiated applications, critical exploration of new uses for this unique product is warranted.

KEY WORDS: Intravenous immunoglobulin; autoimmunity; immunomodulation.

\section{INTRODUCTION}

Antiinflammatory and immunosuppressive drugs have been the primary agents for the treatment of autoimmune disorders. While our understanding of the scope and pathogenic mechanisms of autoimmune diseases has expanded greatly, newer forms of therapy have also been proposed and developed. Included among these are plasmapheresis, antiidio-

${ }^{1}$ Departments of Pediatrics, Microbiology/Immunology, and Epidemiology, The University of Michigan, Ann Arbor, Michigan 48109-2029. typic antibodies, and biological response modifier substances.

Gamma-globulin replacement is the definitive treatment for humoral immunodeficiency disorders. With the advent of intravenous immunoglobulin (IVIG) preparations, therapeutic application was extended to, among other indications, the treatment of idiopathic thrombocytopenia purpura (ITP). Because of the role of antiplatelet antibodies in the pathogenesis of ITP, it can be considered to have an underlying autoimmune etiology. The mechanism(s) of action of IVIG in the treatment of ITP remains poorly understood. However, two hypotheses have gained popularity: (i) Fc receptor blockade and (ii) antiidiotypic antibodies directed against the autoantibodies. Based upon earlier use of IVIG in the treatment of ITP associated with antiplatelet autoantibodies, this therapy has been extended to the wide variety of other autoimmune disorders. Gupta (1) has previously described many of these applications; the present review updates and extends his earlier report. As used herein the definition of autoimmune disease is very broad and encompasses a host of conditions where the underlying immunopathogenic mechanisms include the presence of autoantibodies.

\section{SPECIFIC DISEASES}

\section{Idiopathic Thrombocytopenia Purpura}

Although the original and primary indication for IVIG replacement therapy remains antibody defi- 
ciency states, its use in the treatment of both acute and chronic ITP has also been approved. Imbach and colleagues (2) were the first to report on the efficacy of treatment of ITP of childhood with high-dose IVIG. The initial rationale for this form of therapy was the observation that two congenitally agammaglobulinemic patients with severe thrombocytopenia manifested significant increases in platelet counts after administration of IVIG. IVIG was also found to be effective in treating thrombocytopenia associated with the Wiskott-Aldrich syndrome (3), a disorder in which the presence of platelet-associated antibodies has been described (4). From these earlier studies numerous others have emerged (see Ref. 5 for a review). As the subject of IVIG for the treatment of ITP has been extensively reviewed previously, only a limited discussion is presented here. Lusher and Warrier (6) specifically distinguished between the use of IVIG to treat acute, postinfectious ITP of childhood and its use to treat chronic, autoimmune ITP, which generally affects adults. While the former is often a benign, self-limited disease with a high probability of spontaneous remission, the latter tends to be resistant to corticosteroids and may thus be more amenable to IVIG therapy, possibly in preparation of splenectomy.

Management of acquired, immune thrombocytompenias with IVIG has also been described by several investigators. It has been shown that thrombocytopenia due to alloimmunization after platelet transfusions can be ameliorated by high-dose IVIG therapy (7-11), as can posttransfusion purpura (12, 13), neonatal immune thrombocytopenia (14-16), and autoimmune thrombocytopenia of pregnancy $(17,18)$. Although the latter syndromes are not classical autoimmune disorders as they reflect $d e$ novo sensitization, nevertheless, their underlying pathogenic mechanisms are very similar to autoimmune phenomena.

\section{Hemophilia Associated with Antihemophilic Factor Inhibitors}

While classic hemophilia is an X-linked disorder of blood coagulation due to a nonfunctional variant of antihemophilic factor (factor VIII), acquired inhibitors of antihemophilic factor have been described which cause a coagulopathy clinically similar to hemophilia. These inhibitors have been identified as antibodies. A 39-year-old patient with hemophilia $B$ was found to have circulating antibod- ies capable of functionally inhibiting factor IX (19). These antibodies were probably of the IgG class, as they could be removed by protein A-Sepharose chromatography. However, when extracorporeal treatment by protein $\mathrm{A}-\mathrm{Sepharose}$ adsorption was attempted, the patient subsequently developed a 15 fold increase in antibody titer. When immunoadsorption was followed by IVIG, no such rebound phenomenon was observed, and it was followed up by a prolonged suppression of anti-factor IX antibody production.

Replacement therapy with purified factor VIII for the treatment of hemophilia is sometimes complicated by the development of inhibitory antibodies against factor VIII. Two such patients treated with high-dose IVIG, however, showed a significant rise in inhibitor titers after treatment (20). In contrast, two other reports described the successful treatment of patients with hemophilia $\mathrm{A}$ and serum factor VIII inhibitors $(21,22)$. Clinical improvement was paralleled by the disappearance of inhibitory anti-factor VIII antibodies and resulted in prolonged remission lasting at least 7 months. Followup was unavailable. At present it is not possible to predict which patients with hemophilia and antihemophilic factor antibodies will respond to IVIG. Although empirical therapy can resolve the question, it must be pointed out that such treatment has been complicated by a significant rise in inhibitor titers, thus making factor VIII replacement even more difficult.

Sultan and colleagues demonstrated that treatment of hemophilia due to autoantibodies against antihemophilic factor (factor VIIIc) with IVIG was associated with the presence of antiidiotypic antibodies against the pathologic autoantibodies within the immunoglobulin preparation (23). This was based on the observation that the in vivo clinical response was correlated with the ability of an $\mathrm{F}\left(\mathrm{ab}^{\prime}\right)_{2}$ fraction of the immunoglobulin preparation to reverse the inhibition of factor VIII activity by autoantibodies from hemophiliac patients in vitro.

\section{Autoimmune Hemolytic Anemia}

Immunosuppressive drugs with or without plasmapheresis or splenectomy have been the principal treatment modalities for severe autoimmune hemolytic anemias. Earlier reports suggested that IVIG therapy was ineffective in treating autoimmune hemolytic anemia particularly of the "warm" (IgG- 
mediated) type $(24,25)$. However, IVIG has been used to successfully treat a case of Evans syndrome, refractory autoimmune hemolytic anemia with ITP (26). The rationale for the use of IVIG in this setting was its previously demonstrated efficacy in ITP and presumed similar immunopathogenesis of hemolysis and thrombocytopenia. In this case of a 5-month-old boy, who failed to respond to highdose pulse therapy with corticosteroids and subsequent cyclophosphamide administration, remission was achieved rapidly after two courses of $1.6 \mathrm{~g}$ of IVIG $/ \mathrm{kg}$ given over 4 days. Although the patient was also on chronic prednisone, it was gradually withdrawn and discontinued after IVIG treatment without relapse. Similarly a 75 -year-old man with idiopathic warm autoimmune hemolytic anemia who had been unsuccessfully treated with prednisone, azathioprine, and splenectomy showed immediate but transient improvement after two courses of high-dose IVIG (27). A third course of treatment resulted in a prolonged remission. IVIG has been deemed particularly useful when autoimmune hemolytic anemia is associated with immunodeficiency syndromes (28). Several other reports substantiate the use of IVIG in autoimmune hemolytic anemias due to hemolytic antibodies of the $\mathrm{IgG}$ class (29-31).

Although pure red-cell aplasias are distinctly different from hemolytic anemias in that erythroid precursor cells of the bone marrow are usually absent in the former, many cases of pure red-cell aplasia may be due to immune suppression of erythropoiesis by IgG autoantibodies. McGuire et al. described the successful treatment of a 4year-old girl with antibody-mediated, pure red-cell aplasia (32). Since both $F\left(a b^{\prime}\right)_{2}$ fragments and intact IgG molecules from pooled donor gamma-globulin could reverse the cytotoxic activity of the patient's IgG fraction on hematopoietic progenitor cells in vitro, they concluded that the therapeutic effect may be due to antiidiotypic antibodies recognizing the patient's IgG autoantibodies.

One patient, a 60 -year-old man, with a presumed autoimmune pure white-cell aplasia has also been treated with high-dose IVIG (33). Although a rapid remission was achieved, it was short-lived, requiring other therapeutic intervention.

\section{Autoimmune Neutropenia}

Only a few studies have demonstrated the efficacy of IVIG in the treatment of autoimmune neutropenia. An early report by Pollock et al (34) showed a transient response of autoimmune neutropenia to high-dose IVIG. It was subsequently demonstrated that IVIG produced a more protracted improvement in two symptomatic children with autoimmune neutropenia of infancy (35). The in creased neutrophil count was associated with normal functions and evidence was presented suggesting that IVIG may work through $\mathrm{Fc}$ receptor blockade and/or decreased antineutrophil antibody synthesis. Similar positive effects of IVIG on autoimmune neutropenia were also observed in other studies (36-38).

Felty's syndrome is an autoimmune disease consisting of neutropenia, splenomegaly, and rheumatoid arthritis. The neutropenia appears to be secondary to production of antineutrophil antibodies. Several patients with Felty's syndrome have been treated with IVIG but failed to respond to therapy $(39,40)$. As this observation conflicts with reports of the successful treatment of other immune cytopenias with IVIG, it has been suggested that the neutropenia of Felty's syndrome may involve different pathologic mechanisms (40).

Murakami et al. (41) reported an interesting dissociation between the response of autoimmune neutropenia and thrombocytopenia in a 15-year-old girl. The neutropenia initially responded to IVIG but the thrombocytopenia did not. On subsequent treatment both neutrophil and platelet counts increased significantly. Again, it was suggested that different immunopathogenic mechanisms may be involved in various autoimmune cytopenias.

In another case of combined autoimmune thrombocytopenia and neutropenia, Ricevuti et al. examined the effect of exogenous IVIG on a variety of neutrophil functions (42). Most significantly was the coincident improvement of depressed neutrophil chemotaxis after treatment. This was paralleled by a disappearance in antineutrophil autoantibodies over a 6-day period. Within 30 days, antineutrophil antibodies reappeared and neutrophil numbers and chemotaxis were again depressed. It was also interesting to note that the serum of the untreated patient could suppress the mobility of normal donor neutrophils, but after IVIG treatment the patient's serum was no longer inhibitory. After 30 days, the patient's serum was again suppressive of chemotaxis coincident with the return of neutropenia and antineutrophil antibodies. 


\section{Myasthenia Gravis}

Myasthenia gravis (MG) is an autoimmune disorder wherein autoantibodies to the acetylcholine receptor at the myoneural junction block normal transmission of impulses from the nerve terminus to the muscle fiber. Clinical manifestations of MG include motor weakness and easy fatigability. Therapy of MG includes the use of anticholinesterases to potentiate and prolong the signal at the motor end plate as well as immunosuppressive therapy including corticosteroids and azathioprine. Early preliminary reports suggested that high-dose IVIG could result in neurologic improvement and dimunition of acetylcholine receptor antibodies $(43,44)$. While improvement has been further reported in MG (44, 46), no change in acetylcholine receptor antibodies was noted in another study (47). In a more extensive series and report, Arsura et al. described similar beneficial effects of high-dose IVIG to treat and produce sustained improvement in 11 patients with MG (48). It was interesting to note that the response to IVIG therapy was independent of a variety of parameters including previous therapy, coexisting thymoma, or a history of thymectomy. In contrast to some previous reports, no depression of elevated acetylcholine receptor antibody titers was observed despite clinical improvement.

Cook and her colleagues have described some interesting changes in immunologic parameters occurring during the course of IVIG treatment of MG (49). While a slight decrease in the total number of circulating lymphocytes was observed, $\mathrm{CD} 16^{+}$and $\mathrm{CD}^{+}$mononuclear leukocytes showed a significant increase proportionate to the serum level of IgG achieved. The authors speculated that these might represent natural killer cells. Other findings included an increase in IgG-specific, Fc receptorbearing cells which could potentially be suppressor T lymphocytes and decreases in the absolute number of helper $T$ cells. The latter observations may partially elucidate the immunoregulatory mechanisms underlying the efficacy of high-dose IVIG for the treatment of MG.

\section{Seizure Disorders}

The inclusion of seizure disorders within the category of autoimmune diseases is admittedly arbitrary. However, evidence does exist for the role of immunologic mechanisms in the pathogenesis of some forms of epilepsy (50). Several investigators have utilized IVIG for the treatment of intractable childhood epilepsies, with a wide range of results (51-56). Although perceived clinical improvement could occasionally be correlated with objective neurologic evidence, all of these reports lacked rigorous controls.

Regarding hypothetical mechanisms of action of IVIG in the treatment of seizures, it is interesting to note that for some of the specific seizure types described, immunosuppressive drugs (e.g., adrenocorticotropic hormone and/or corticosteroids) have been used in conjunction with anticonvulsants. Thus one could speculate that IVIG may be operating through a putative immunomodulatory mechanism. In seizures associated with a specific immunodeficiency $(57,58)$, IVIG may be exerting an effect against an etiologic agent. Again, these questions will only be resolved with large-scale, wellcontrolled, prospective clinical trials.

\section{Multiple Sclerosis (MS)}

MS is a demyelinating disease of unknown etiology; however, considerable evidence exists for the role of immune mechanisms in its pathogenesis. A popular model includes a proposed initial viral infection followed by a secondary autoimmune process, principally directed at the perineural myelin sheaths. In extreme reactions the axis cylinders are also affected. Therapy has generally consisted of immunosuppressive drugs, principally ACTH and corticosteroids, plus symptomatic treatment. However, several investigators, primarily in Europe, have also employed IVIG. These trials, like numerous others described herein, have been unblinded and nonrandomized with minimal controls. In an early attempt at using IgG to treat MS, Schuller and Govaerts (59) initially used intramuscular gammaglobulin, $5 \mathrm{~g}$, given three times per week. This was subsequently changed to IVIG, $5 \mathrm{~g}$, given once weekly. Their cohorts consisted of 31 MS patients with a mean duration of therapy of 4 years. The clinical course of these patients was compared to that of a control group of 164 patients receiving conventional therapy. Three response profiles were observed: (i) improvement (11 patients), (ii) no changes (9 patients), and (iii) deterioration (11 patients). When compared to the course of the controls, the degree of improvement noted in the first group was statistically significant by several tests.

In another trial Rothfelder et al. (60) treated 20 MS patients with $5 \mathrm{~g}$ of IVIG administered every 2 
months. Some clinical improvement, primarily in extremity symptoms, was noted, as well as a decrease in the frequency of exacerbations. These authors concluded that more extensive and bettercontrolled additional trials are warranted.

A summary of the experience of using gammaglobulin to treat MS has recently been published (61). While it was recognized that it is still too early to judge the efficacy of gamma-globulin in the treatment of MS, it was also noted that some patients with severe, progressive exacerbations seemed to experience rapid neurological improvement with gamma-globulin treatment.

\section{Inflammatory Polyneuropathy}

Chronic ployneuropathies can occur in conjunction with other disorders such as infections, malignancies, and collagen-vascular diseases or they may be idiopathic in origin. While their underlying pathologic mechanisms may be obscure, the frequent occurrence of mononuclear infiltrates of the affected nerves suggests the possibility of associated immunopathology. Accordingly Vermeulen and colleagues have treated 17 patients with chronic inflammatory polyneuropathy with fresh-frozen plasma or high-dose IVIG (62). Improvement was observed in 13 of these patients. The rationale for this therapy was based on the effects of IVIG for ITP. Of particular significance was the observation that improvement was seen after plasma or IVIG, in spite of the fact that no spontaneous remissions had been noted for 2 months prior. When plasma or IVIG was discontinued, the patients deteriorated clinically; however, upon reinstituting treatment they experienced significant improvement. Although the treatment effect was short-lived, improvement could be reestablished with plasma or IVIG infusions, without any indication of becoming refractory to chronic therapy. The authors further suggest trials of IVIG for acute polyneuropathies.

\section{Systemic Lupus Erythematosus (SLE)}

Only a limited experience with IVIG treatment of SLE has been reported to date. Gaedicke et al. described the widely disparate responses of two adolescent girls with SLE to treatment with highdose IVIG (63). While one patient achieved a longlasting remission of a serious, acute exacerbation, no effect was seen with the other patient. It was implied that IVIG may be effective for ameliorating severe acute exacerbations of SLE but may not be of use in chronic disease, which may explain the different responses observed.

Additional reports have also indicated marginal effects of IVIG on SLE. When six patients with SLE were treated with high-dose IVIG, the only clinical response was a brief improvement in their thrombocytopenia (64). Other symptoms generally remained unchanged; however, proteinuria increased secondary to IgG appearing in the urine. Circulating immune complexes, which were elevated prior to therapy, showed significant posttreatment reductions. Two infants born to mothers with active SLE who showed significantly decreased platelets and polymorphonuclear neutrophils soon after birth were treated with IVIG (65). Rapid amelioration of the children's cytopenias was observed. Recently two independent groups described the use of IVIG for several different patients with various collagen vascular disorders including SLE, juvenile rheumatoid arthritis, polymyositis, and Sjogren's syndrome $(66,67)$. While improvement and steroid sparing activity was noted, some of the effects were transient. These observations suggest that criteria for patient selection and optimal dosage remain to be determined.

Although several unpublished reports on the use of IVIG in the treatment of SLE, including lupus glomerulonephritis, have also been presented at various meetings, it is still premature to determine the role of this therapy for SLE. More extensive, well-controlled trials may soon resolve this issue.

\section{Rheumatoid Arthritis}

Like SLE, a paucity of published studies begs the question of whether IVIG may be useful in the treatment of rheumatoid arthritis (RA). In a very early report, Sany and co-workers describe the treatment of 10 hospitalized patients with severe RA using intravenous administration of a gammaglobulin preparation derived from human placentas (68). Significant but transient clinical improvement was noted in seven patients. A concomitant increase in both lymphocyte mitogen responses and percentages of "active" (E-rosette) $T$ cells was also observed. In a much larger series of 31 patients with RA, approximately $60 \%$ of the study population experienced significant clinical improvement after the intravenous administration of a similar placentaderived gamma-globulin preparation (69). While variable improvements were noted with regard to 
the sedimentation rate and levels of rheumatoid factor, ANA, and levels of circulating immune complexes, all patients showed increased active $\mathrm{E}$ rosette-forming cells and a short-lived decline in Fc receptor-bearing lymphocytes. It was implied that in both of these studies the placental source of the gamma-globulins may have endowed them with unique immunosuppressive properties (e.g., antiHLA-DR activity).

\section{Kawasaki Syndrome}

Kawasaki disease (KD) or mucocutaneous lymph node syndrome consists of a constellation of signs and symptoms including (i) fever of unknown etiology lasting 5 days or more, (ii) bilateral injection of the ocular conjunctivae, (iii) perioral and oropharyngeal changes and inflammation, (iv) cervical adenitis, ( $v$ ) involvement of extremities (palmar and plantar erythema, edema, and desquamation), and (vi) polymorphous truncal examthem (70). Although the basic pathogenic mechanisms underlying $\mathrm{KD}$ are presently poorly understood, nevertheless, much evidence indicates that it may be an immunologically medicated disorder. Because of a presumed immunologic basis for $\mathrm{KD}$, especially the presence of potentially pathologic soluble circulating immune complexes, Furosho et al. undertook a multicenter, controlled trial of high-dose IVIG plus aspirin versus aspirin alone for the treatment of patients with KD (71). They reported that the IVIG regimen appeared to reduce the frequency of coronary artery abnormalities. These results were confirmed in a subsequent controlled, American study (72). Hence the Committee on Infectious Diseases of the American Academy of Pediatrics has issued guidelines for the use of IVIG in children with KD (73). Recently, however, Mason et al. examined the effects of IVIG on circulating immune complexes (CICs) in patients with CD (74). Although increased levels of CICs were noted, IVIG therapy did not appear to decrease their prevalence. Hence the authors concluded that CICs are not likely to be the primary immunopathologic mechanism of $\mathrm{KD}$.

$\mathrm{KD}$ has been the subject of much clinical and basic research (75). Several investigators have focused on a possible infectious etiology. Until these issues are resolved, high-dose IVIG therapy instituted within 10 days after the onset of disease appears to reduce significantly the morbidity and mortality of associated cardiovascular complications (76).

\section{Insulin-Dependent Diabetes Mellitus (IDDM)}

Considerable evidence exists to support an autoimmune basis for IDDM or type I diabetes. In addition to the demonstration of islet cell-specific autoantibodies in serum during the onset of disease, postmortem examinations have also revealed coexisting infiltration of the islets of Langerhans with $T$ lymphocytes (i.e., "insulitis"). Recent studies have indicated that immunomodulatory agents such as cyclosporin A may retard progression of disease (77). In an uncontrolled clinical trial, six children with recently diagnosed IDDM were treated with high-dose IVIG for up to 6 months (78). Four children demonstrated a prolonged partial remission.

A larger, controlled trial of high-dose IVIG using 20 newly diagnosed patients, also treated for up to 6 months, further indicated that this form of therapy may be an adjunct to conventional treatment (79). Most significant was a difference in insulin requirements between the treated and the untreated patients, with the latter necessitating a larger maintenance dose than the former. Accompanying the decreased insulin requirement was a concomitant increase in serum C-peptide levels. No other immunologic parameters showed any differences between the treated and untreated groups.

These intriguing observations warrant further follow-up, as cyclosporin A is associated with serious side effects; perhaps combination therapy with high-dose IVIG may permit a dosage reduction of the former while retaining efficacy.

\section{Bullous Pemphigoid}

Bullous pemphigoid is a severe, autoimmune blistering disease secondary to autoantibodies which recognize antigens of the basement membrane. Conventional therapy for pemphigoid usually consists of steroids, immunosuppressive drugs, and/or plasmapheresis. Godard and colleagues described the treatment of 11 patients with bullous pemphigoid with IVIG (80). Rapid but transient responses were noted in eight patients, only one of whom had a prolonged remission. The authors speculate that combination therapy of IVIG with steroids may have a steroid-sparing effect.

\section{PROPOSED MECHANISMS OF ACTION}

While the rationale of IVIG replacement therapy for antibody deficiency states is obvious, its role as 
an immunomodulating agent is less well understood. Several hypotheses have been evoked to explain the mechanisms by which IVIG may be effective in treating the numerous autoimmune disorders previously described. It is beyond the scope of this report to present these theories in detail. Rather, a brief summary of several currently popular propositions is described.

The efficacy of intact, native IgG as an immunomodulator is consistent with a model which suggests that unbound IgG, particularly when in excess, may compete with IgG complexed to antigens for $\mathrm{Fc}$ receptors on the surface of phagocytic cells in circulation and within the reticuloendothelial system. These cells are very effective in eliminating immune complexes (e.g., antibodies bound to cellular components such as RBCs, PMNs, platelets, hematopoietic stem cells, etc.) Thus blockage of Fc receptors with unbound IgG may inhibit destruction of autoantibody-bearing cells.

Jerne's network theory of immunoregulation is conceptually dependent upon the existence of naturally occurring antiidiotypic antibodies in circulation (81). Antiidiotypic antibodies specific for the idiotypes of various autoantibodies may be constitutively present in the serum of healthy individuals as a normal immunoregulatory mechanism. These antiidiotypic antibodies may selectively target plasma cells or other members of the B-lymphocyte lineage bearing membrane-bound autoantibodies for complement-dependent and/or cell-mediated cytotoxicity, thereby eliminating potential clones of autoantibody-producing cells.

The role of infectious agents has also considered in the pathogenesis of some autoimmune reactions. Binding of antigens from etiologic agents to host cells may initiate an autoimmune response to the complex of neoantigen plus host-cell ("self"') antigens. The elimination of the infectious agent with IVIG could thus break such a vicious cycle.

Support for one or several of the above proposals may be found in the literature. Only additional studies, both in vivo and in vitro, will define the mechanisms underlying the well-demonstrated immunomodulatory activities of IVIG.

\section{ACKNOWLEDGMENTS}

The author expresses his appreciation to Denise DuPrie for her excellent secretarial assistance and to the National Cancer Institute for research support from Grant CA35922.

\section{REFERENCES}

1. Gupta S: Current and future uses of intravenous gamma globulin in autoimmune disorders. Immunol Allergy Pract $3: 370-377,1986$

2. Imbach $P$, d'Apuzzo V, Hirt A, Rossi E, Vest M, Barundun S, Baumgartner C, Morell A, Schoni M, Wagner HP: High dose intravenous gammaglobulin for idiopathic thrombocytopenic purpura in childhood. Lancet 1:1228-1230, 1981

3. Imbach P, Barandun S, Baumgartner C, Hirt A, Hofer F, Wagner HP: High dose intravenous gammaglobulin therapy of refractory, in particular idiopathic thrombocytopenia in childhood. Helv Paediat Acta 36:81-86, 1981

4. Lum LG, Tubergen DG, Corash L, Blaese RM: Splenectomy in the management of the thrombocytopenia of the Wiskott-Aldrich syndrome. N Engl J Med 302:892-896, 1980

5. Bussel JB: Intravenous immunoglobulin therapy for the treatment of idiopathic thrombocytopenia purpura. Prog Hemost Thromb 8:103-158, 1986

6. Lusher JM, Warrier I: Use of intravenous gamma globulin in children and adolescents with idiopathic thrombocytopenic purpura and other immune thrombocytopenias. Am J Med 83 (Suppl 4A):10-16, 1987

7. Becton DL, Kinney TR, Chaffee S, Kartzberg J, Friedman, HS, Falletta JM: High-dose intravenous immunoglobulin for severe platelet alloimmunization. Pediatrics 74:1120-1122, 1984

8. Junghans RP, Ahn YS: High-dose intravenous gamma globulin to suppress alloimmune destruction of donor platelets. Am J Med 76 (Suppl 3A):204-208, 1984

9. Schiffer CA, Hogge DE, Aisner J, Dutcher JP, Lee EJ, Papenberg D: High dose intravenous gammaglobulin in alloimmunized platelet transfusion recipients. Blood 64:937940,1984

10. Knupp C, Chamberlain JK, Raab SO: High-dose intravenous gamma globulin in autoimmunized platelet transfusion recipients. Blood 64:937, 1984

11. Kurtzberg J, Friedman HS, Kinney TR, Chaffee S, Falletta JM: Treatment of platelet alloimmunization with intravenous immunoglobulin. Two case reports and review of the literature. Am J Med 83 (Suppl 4A):30-33, 1987

12. Becker T, Panzer S, Maas D, Kiefel V, Sprenger R, Kirschbaum M, Mueller-Eckhardt C: High dose intravenous immunoglobulin for post-transfusion purpura. $\mathrm{Br} \mathrm{J}$ Hematol 61:149-155, 1985

13. Berney SI, Metcalfe P, Wathen NC, Waters AN: Post transfusion purpura responding to high dose intravenous IgG: Further observations on pathogenesis. Br J Haematol $61: 627,1985$

14. Sidiropoulos D, Straume B: The treatment of neonatal isoimmune thrombocytopenia of childhood with intravenous immunoglobulin (IgGIV). Blut 48:383, 1984

15. Castaman G, Rodeghiero F, Ronioni GF, Dini E: Successful treatment of neonatal "autoimmune" thrombocytopenia with high-dose intravenous immunoglobulins. Hematologica (Pavia) 70:276-277, 1985 (letter)

16. Ekert H: Intravenous immunoglobulin versus oral corticosteroids in acute immune thrombocytopenic purpura in childhood. Lancet 2:1310, 1985 (letter)

17. Hegde UM: Immune thrombocytopenia in pregnancy and the newborn: A review. J Infect 15 (Suppl 1):55-58, 1987 
18. Morgenstern GR, Measday, B, Hegde UM: Autoimmune thrombocytopenia in pregnancy: New approach to management. Br Med J 287:584, 1983

19. Nilsson IM, Sundquist SB, Ljang R, Holmberg L, Freiburghaus C, Bjorlin G: Suppression of secondary antibody response by intravenous immunoglobulin in a patient with hemophilia B and antibodies. Scand J Haematol $30: 458-464,1983$

20. Seifried E, Gaedicke G, Pindus G, Rasche H: The treatment of hemophilia $A$ with high dose intravenous immunoglobulin. Blut 48:397-401, 1984

21. Gianella-Borradori A, Hirt A, Luthy A, Wagner HP, Imbach P: Haemophilia due to factor VIII inhibitors in a patient suffering from an autoimmune disease: Treatment with intravenous immunoglobulin. Blut 48:403-407, 1984

22. Zimmerman R, Kommarell B, Harenburg J, Eich W, Rother $\mathrm{K}$, Schimpf KL: Intravenous IgG for patients with spontaneous inhibitor to factor VIII. Lancet 1:273-274, 1985

23. Sultan Y, Kazatchkine MD, Maisomeune P, Nydegger UE: Anti-idiotypic suppression of autoantibodies to factor VIII (antihaemophilic factor) by high-dose intravenous gammaglobulin. Lancet 2:765-768, 1984

24. Fehr J, Hoffman V, Kappeler U: Transient reversal of thrombocytopenia in idiopathic thrombocytopenic purpura by high-dose intravenous gamma globulin. N Engl J Med 306:1254-1258, 1982

25. Salama A, Mueller-Eckhardt C, Kieffel V: Effect of intravenous immunoglobulin in immune thrombocytopenia. Lancet 2:193-194, 1983

26. Oda $H$, Honda $H$. Sugita $K$, Nakamura A, Nakajima $H$ : High-dose intravenous intact $\mathrm{IgG}$ infusion in refractory autoimmune hemolytic anemia (Evans syndrome). J Pediat $107: 744-746,1985$

27. Macintyre EA, Linch DC, Macey MG, Newland AC: Successful response to intravenous immunoglobulin in autoimmune haemolytic anemia. Br J Haematol 60:387-388, 1985

28. Porecco M, Ventura A, Tamaro P, Longo F: High-dose IVIgG in autoimmune hemolytic anemia. J Pediat 109:726, 1986 (letter)

29. Bussel JB, Cunningham-Rundles C, Abraham C: Intravenous treatment of autoimmune hemolytic anemia with very high dose gammaglobulin. Vox Sang 51:264-269, 1986

30. Richmond GW, Ray I, Korenblitt A: Initial stabilization preceding enhanced hemolysis in autoimmune hemolytic anemia treatment with intravenous gammaglobulin. J Pediat 110:917-919, 1987

31. Sasaki H, Akutagawa H, Kuwakado K, Uemura M, Emi I: High-dose intravenous IgG therapy in a seven-week-old infant with chronic autoimmune hemolytic anemia. Am J Hematol 25:215-218, 1987

32. McGuire WA, Yang HH, Bruno E, Brandt J, Briddell R, Coates TD, Hoffman R: Treatment of antibody-mediated pure red-cell aplasia with high-dose intravenous gamma globulin. N Engl J Med 317:1004-1008, 1987

33. Barbui T, Bassan R, Viero P, Minetti B, Comotti B, Buelli M: Pure white cell aplasia treated by high dose intravenous immunoglobulin. Br J Haematol 58:554-555, 1984 (letter)

34. Pollack S, Cunningham-Rundles C, Smithwick EM, Barandun S, Good RA: High dose intravenous gammaglobulin in autoimmune neutropenia. $\mathrm{N}$ Engl J Med 307:252, 1982

35. Bussel J, Lalezari P, Hilgartner M, Partin J, Fikrig S, O'Malley J, Barandun S: Reversal of neutropenia with intravenous gammaglobulin in autoimmune neutropenia of infancy. Blood 62:398-400, 1983

36. Hilgartner MW, Bussel J: Use of intravenous gamma globulin for the treatment of autoimmune neutropenia of childhood and autoimmune hemolytic anemia. Am J Med 83 (Suppl 4A):25-29, 1987

37. Bussell J, Lalezari P, Fikrig S: Intravenous treatment with gammaglobulin of autoimmune neutropenia of infancy. $J$ Pediat 112:298-301, 1988

38. Kurtzberg J, Friedman HS. Chaffee S, Falletta JM, Kininey TR, Kurlander R, Matthews TJ, Schwartz RS: Efficacy of intravenous gamma globulin in autoimmune-mediated pediatric blood dyserasias. Am J Med 83 (Suppl 4A):4-9, 1987

39. Ahern M, Harkness J, Maddison P, Forskitt S: High-dose immunoglobulin in Felty's syndrome. Ann Rheum Dis 42:476-477, 1983 (letter)

40. Breedveld FC, Brand A, VanAken WG: High dose intravenous gamma globulin for Felty's syndrome. J Rheumato 12:700-702, 1985

41. Murakami H, Kikuchi M, Toyama K, Ikeda Y: A case of autoimmune neutropenia and thrombocytopenia: Effect of high-dose intravenous immunoglobulin. Keio J Med 34:227232,1985

42. Ricevuti G, Mazzone A, Rizzo SC: A study of neutrophil function in a case of associated autoimmune neutropenia and thrombocytopenia treated with high doses of intravenous gammaglobulin (HDIGG). Clin Lab Haematol 8:325-335, 1986

43. Gajdos $\mathrm{PH}$, Outin $\mathrm{H}$, Elkhanat D: High dose intravenous gammaglobulin for myasthenia gravis. Lancet 1:406-407, 1984 (letter)

44. Fateh-Maghadam A, Besinger U, Geursen RG: High dose intravenous gamma globulin for myastenia gravis. Lancet 1:848-849, 1984 (letter)

45. Arsura EL, Bick A, Brunner NG, Namba T, Grob D: Highdose intravenous immunoglobulin in the management of myasthenia gravis. Arch Intern Med 146:1365-1368, 1986

46. Devathasan $G$, Kuch YK, Chong PN: High-dose intravenous gammaglobulin for myasthenia gravis. Lancet $2: 809$ 810,1984

47. Ippoliti G, Cosi V, Piccolo G, Lombardi M, Mantegaz R: High-dose intravenous gammaglobulin for myasthenia gravis. Lancet $2: 809,1984$

48. Arsura E, Bick A, Brunner NG, Grob D: Effects of repeated doses of intravenous immunoglobulin in myasthenia gravis. Am J Med Sci 295:438-443, 1988

49. Cook L, Howard JF Jr, Folds JD: Immediate effects of intravenous IgG administration on peripheral blood $\mathrm{B}$ and $\mathrm{T}$ cells and polymorphonuclear cells in patients with myasthenia gravis. J Clin Immunol 8:23-31, 1988

50. Walker AE: Allergic phenomena as basic mechanisms in epilepsy. In Basic Mechanisms of the Epilepsies, HH Jasper, AA Ward, A Pope (eds). London, Churchill, 1969, p 812

51. Pechadre JC, DeVillepin A, Sauvezi B. Gibert J: Gammaglobulines et epilepsie. Rev Med 34:1889-1901, 1978

52. Laffont F, Esnault S, Gilbert A, Peytour MA, Cathola HP, Eygonnet JP: Effets des gammaglobulines sur des epilepsies rebelles. Etude preliminaire. Ann Med Interne (Paris) $130: 307-312,1979$

53. Ariizumi M, Shiihara H, Hibio S, Ryo S, Baba, K, Ogawa K, Suzuki Y, Momoki T: High dose gamma globulin for intractable childhood epilepsy. Lancet 2:162-163, 1983 
54. Sandstedt $\mathbf{P}$, Kostulas V, Larsson LE: Intravenous gammaglobulin for post-encephalitic epilepsy. Lancet 2:1154-1155, 1984

55. Bedimi R, de Feo MR, Orano A, Rocchi L: Effects of gamma globulin therapy in severely epileptic children. Epilepsia 26:98-102, 1985

56. Schwartz SA, Gordon KE, Johnston MN, Goldstein GW: Use of intravenous immune globulin in the treatment of seizure disorders. J Allergy Clin Immunol 84:603-607, 1989

57. Duse $M$, Tibert $S$, Plebani $M$, Avanzini MA, Gardenghi $M$, Menegati E, Morrafo $V$, Ugazio AG: IgG2 deficiency and intractable epilepsy of childhood. Monogr Allergy 20:128134,1986

58. Erlendsson K, Swartz T, Dwyer JM: Successful reversal of echovirus encephalitis in X-linked hypogammaglobulinemia by intraventricular administration of immunoglobulin. $\mathrm{N}$ Engl J Med 312:351-353, 1985

59. Schuller E, Govaerts A: First results of immunotherapy with immunoglobulin $\mathrm{G}$ in multiple sclerosis patients. Eur Neurol $22: 205-212,1983$

60. Rothfelder U, Neu I, Pelka R: Therapie der multiplen sklerose mit immunglobulin G. Munch Med Wochenschr 124(4):74-78, 1982

61. Soukop W, Tschabitscher H: Gammaglobulintherapie bei multipler sklerose (MS). Theoretische uberlegungen und erste klinische erfahrungen mit $7 \mathrm{~S}$-immunoglobulin in der MS-therapie. Wien Med Wochenschr 136:477-480, 1986

62. Vermeulen M, van der Meche FGA, Speelman JD, Weber A, Busch HFM: Plasma and gamma-globulin infusion in chronic inflammatory polyneuropathy. J Neurol Sci 70:317326,1985

63. Gaedicke G, Teller WM, Kahne E, Dopfer R, Niethammer $\mathrm{D}$ : IgG therapy in systemic lupus erythematosus-two case reports. Blut $48: 387-390,1984$

64. Lin $\mathrm{RY}$, Racis SP: In vivo reduction of circulating $\mathrm{Clq}$ binding immune complexes by intravenous gammaglobulin administration. Int Arch Allergy Appl Immunol 79:286-290, 1986.

65. Hanada T, Saito $K$, Nagasawa T, Kabashima T, Nakahara $S$, Okuyama A, Takita $\mathrm{H}$ : Intravenous gammaglobulin therapy for thromboneutropenic neonates of mothers with systemic lupus erythematosus. Eur J Haematol 38:400-404, 1987

66. Ballow M, Parke A: The uses of intravenous immune globulin in collagen vascular disorders. J Allergy Clin Immunol 84:608-612, 1989

67. Gelfand EW: The use of intravenous immune globulin in collagen vascular disorders: A potentially new modality of therapy. J Allergy Clin Immunol 84:613-616, 1989
68. Sany J, Clot J, Bonneau M, Andacy M: Immunomodulating effect of human placenta eluted gamma globulins in theumatoid arthritis. Arth Rheum 25:17-24, 1982

69. Combe B, Corso B, Clot J, Bonneau M, Sany J: Human placenta-eluted gamma globulins in immunomodulating treatment of rheumatoid arthritis. Am J Med 78:920-928. 1985

70. Morens DM, Anderson LJ, Hurwitz ES: National surveillance of Kawasaki disease. Pediatrics 65:21-25, 1980

71. Furosho K, Kamiga T, Nakana H, Kiyosawa N, Shinomiya $K$. Hayashidera $T$, Tomara $T$, Hirose $O$, Manabe $Y$, Yokoyama T, Kawarano M, Baba K, Baba K, Mori C: High dose intravenous gamma globulin for Kawasaki disease. Lancet 2:1055-1058, 1984

72. Newburgh JW, Takahashi M, Burns JC, Beiser AS, Chung KJ, Duffy CE, Glode MP, Mason WH, Reddy V, Sanders SP, Shulman ST, Wiggins JW, Hicks RV, Fulton DR, Lewis $\mathrm{AB}$, Leung DYM, Colton T, Rosen FS, Melish ME: The treatment of Kawasaki syndrome with intravenous gamma globulin. N Engl J Med 315:341-347, 1986

73. Committee on Infectious Diseases: Intravenous gamma globulin use in children with Kawasaki disease. Pediatrics $82: 122,1988$

74. Mason W, Jordan S, Sakai R, Takahashi M: Lack of effect of gamma-globulin infusion on circulating immune complexes in patients with Kawasaki syndrome. Pediatric Infect Dis $7: 94-99,1988$

75. Shulman ST (ed): Kawasaki disease (Proceedings of the Second Internation Kawasaki Disease Symposium) New York, Alan R. Liss, 1987

76. Rowley AH, Shulman ST: What is the status of intravenous gamma globulin for Kawasaki syndrome? Pediat Infect. Dis J 7:463-466, 1988

77. Geutren G, Papor L, Assan R, Vialattes B. Vexiau P: Cyclosporin increases the rate and length of remission in insulin-dependent diabetes of recent onset. Lancet 2:119124,1986

78. Heinze E, Thon A, Vetter U, Gaedicke G, Zuppinger K: Gamma-globulin therapy in 6 newly diagnosed diabetic children. Acta Paediat Scand 74:605-606, 1985

79. Pocecco M, DeCampo C, Cantoni L, Tedesco F, Fanizon: Effect of high doses intravenous $\operatorname{IgG}$ in newly diagnosed diabetic children. Helv Paediat Acta 42:289-295, 1987

80. Godard W, Roujeau JC, Guillot B, Andre C, Rifle G: Bullous pemphigoid and intravenous gammaglobulin. Ann Intern Med 103-965, 1985 (letter)

81. Jerne NK: The immune system: A web of V-domains. Harvey Lectures, Series 70. New York, Academic Press, 1976 